\title{
Weder Held noch Opfer: Trauma, Identität und die gesellschaftliche Position von Kriegsheimkehrern bei Svetlana Aleksievič, Faruk Šehić und Andrej Gelasimov
}

Die Rollen von Opfer und Täter^in werden obsolet, wenn sie durch dieselbe Person verkörpert sind. Im Falle von Kriegsheimkehrern ist dies in unterschiedlicher Weise stets der Fall, da diese zum einen aktiv am Krieg partizipiert und zum anderen selbst physisches sowie psychisches Leid erlitten haben. Über beides wird am häufigsten anhand der Rollenzuschreibung des Helden hinweggetäuscht, die diesen Widerspruch zu tilgen scheint, indem sie sowohl die Täteridentität als auch die menschliche Schwäche traumatisch Gebrochener relativiert und positiv umdeutet.

Im Folgenden werden Texte von Svetlana Aleksievič, Andrej Gelasimov und Faruk Šehić behandelt, die mit dieser Tradition brechen, indem sie schwache, durch die Kriege in Afghanistan, Tschetschenien und Jugoslawien traumatisierte Persönlichkeiten aus der Innenperspektive zeigen: Die Beispiele verwehren sich einer klaren Festlegung sowohl auf Opfer- als auch auf Täter- oder Heldennarrative, da es zu allen Anknüpfungspunkte zu geben scheint, die sich wechselseitig konterkarieren. Dabei liegen jeweils auch wertende Außenperspektiven auf die Zusammenhänge zwischen Individuum und Krieg vor. Kriegstrauma, Kriegsidentität und Erinnerungskultur sind jene drei Paradigmen, anhand derer im vorliegenden Beitrag versucht wird, die gesellschaftliche Position von Kriegsteilnehmern auszuloten. Alle drei eignen sich zur Verhandlung von Opfernarrativen, da Traumatisierung eine Opferrolle nahelegt, während anhaltende Kriegsinstinkte eher mit Täternarrativen in Verbindung zu stehen scheinen und die spezifischen Diskurse im Rahmen von Erinnerungskulturen oft auf eine klare argumentative Festschreibung von Opfer- und Täterrollen abzielen.

Nach einer Reflexion der durch das Korpus vorgegebenen Gratwanderung zwischen dokumentarischem und literarischem Schreiben stehen in den folgenden Kapiteln ,Kriegstrauma', ,Kriegsidentität‘ und ,Erinnerungskultur‘ im Zentrum. Der in den untersuchten Texten jeweils ähnliche Diskurs um Opfer ohne Anspruch auf eine Opferrolle wird anhand dieser drei Bereiche jeweils indirekt offengelegt: Symptome von Kriegstraumata, wie Angstzustände und Schlafstörungen, zeugen von einer inneren Versehrtheit der betroffenen Kriegsteilnehmer und entziehen Heroisierungsversuchen von vornherein jede Grundlage.

Unter ,Kriegsidentität‘ werden im Folgenden typische reflexbasierte Hand- 
lungsmuster von Kriegsheimkehrern verstanden, welche teilweise vorbereitend für die Kampfhandlungen eingeübt wurden und teilweise angeborenen Schutzmechanismen entsprechen, die durch die Extremsituation in verstärkter Form internalisiert wurden. Alle Texte enthalten Beispiele dafür, dass solche Reflexe unkontrollierbar auch nach dem Krieg fortbestehen. Sowohl aus der Eigen- als auch aus der Fremdperspektive werden sie als unangemessen und stigmatisierend erlebt. Eine Schädigung der Betroffenen durch den Kriegseinsatz ist dabei deutlich erkennbar; da die Kriegsreflexe jedoch aggressives Verhalten triggern, eignen sich diese nicht zur Konstruktion einer Opferrolle.

Unter dem Überbegriff ,Erinnerungskultur‘ werden Versuche der Konstruktion von öffentlichen Helden- und Opferdiskursen behandelt, denen die Primärtexte mit dem Anliegen nachspüren, sie einerseits zu erklären und sich ihnen andererseits implizit zu widersetzen, wodurch ihre kritische Position erkennbar wird. Das letzte Kapitel der vorliegenden Analyse widmet sich dem Umstand, dass die Texte ihrerseits Räume des Gedenkens schaffen, die den versehrten Kriegsteilnehmern gewidmet sind, diesen jedoch weder eine Opfer- noch eine Heldenrolle zuschreiben.

\section{Dokumentarisches, autobiografisches und fiktionales Schreiben}

Das vorliegende Korpus ist heterogen, denn die gewählten Texte unterscheiden sich nicht nur hinsichtlich der nationalen bzw. kulturellen Kontexte ihres Ursprungs und jener des darin verarbeiteten Krieges, sondern auch hinsichtlich ihrer Gattung.

Svetlana Aleksievič publizierte Cinkovye mal'čiki [Zinkjungen] erstmals 1991 als Buch; 1989 war bereits ein Artikel mit Auszügen daraus in der weißrussischen Literaturzeitschrift Litaratura $i$ mastactva erschienen. Es handelt sich um eine dokumentarische Sammlung persönlicher Kriegsberichte auf Basis von Interviews mit Soldaten aus dem Afghanistan-Krieg und deren Angehörigen. Die im weißrussischen Fernsehen übertragene Aufführung einer dramatisierten Fassung und weitere Veröffentlichungen von Auszügen in der Zeitung Komsomol'skaja Pravda führten $1993 \mathrm{zu}$ einem Gerichtsprozess; zwei ihrer Interviewpartner`innen - ein ehemaliger Soldat und die Mutter eines Gefallenen - hatten geklagt, da sie sich in ihrer Würde verletzt fühlten. ${ }^{1}$ Um Auszüge aus den Prozessakten und zahlreiche Pressemeldungen erweitert, erschien 2007 eine Neuauflage.

1 Das Gericht gab einem der Klägerinnen teilweise Recht, weshalb Aleksievič dazu verurteilt wurde, dessen Verfahrenskosten zu tragen. 
Faruk Šehić veröffentlichte den autobiografischen Roman Pod pritiskom [Unter Druck] über seine Teilnahme am Bosnien-Krieg 2003, knapp zehn Jahre nach seinen darin behandelten Erfahrungen. Auch das spätere, erzählende Ich ist deutlich von den Kriegsfolgen gezeichnet; es berichtet durch das Prisma von Erinnerungslücken, Alkohol und traumatischem Wiedererleben. Diese Merkmale sowie Alpträume, Angstzustände, emotionale Instabilität und die Schwierigkeit, in den gewohnten Alltag zurückzufinden, schildern auf sehr ähnliche Weise auch Aleksievičs Zeugen des Afghanistan-Krieges, und sie prägen außerdem die Figuren in Andrej Gelasimovs 2002 erschienener, international ausgezeichneter Novelle Žažda [Durst]. Den Ausgangspunkt dieses dritten Texts bilden ebenfalls reale Erfahrungen, die der Autor aus den Erzählungen von Tschetschenien-Heimkehrern aus seinem Bekanntenkreis übernommen hat $(G, 4){ }^{2}$

Trotz der unterschiedlichen produktionsästhetischen Verhältnisse zwischen direkter bzw. indirekter Kriegserfahrung und Schreiben gleichen die drei Texte einander in der Darstellung des subjektiven Erlebens sowohl von Traumatisierung durch den Krieg als auch der dadurch bedingten Kluft zwischen Individuum und Gesellschaft. Kritisch skizziert wird außerdem jeweils die öffentliche Sicht auf ehemalige Kriegsteilnehmer. Die Schilderungen von Kriegsfolgen auf Basis von Zeugenberichten, erinnernder Rekonstruktion und fiktionaler Formung enthalten daher vergleichbare Momente, die eine sinnvolle Basis für ihre gemeinsame Behandlung im vorliegenden Artikel darstellen.

So unterschiedlich dokumentarisches, autobiografisches und fiktionales Schreiben in Herangehensweise und Poetik auch sind, so bemerkenswert ähnlich ist in den gewählten Texten die Perspektive auf Kriegsheimkehrer. Einen Grund dafür stellt sicherlich die hybride Form aller drei Texte dar, die zwar unterschiedlichen Gattungen zuzuordnen sind, wobei jedoch $\mathrm{zu}$ bedenken bleibt, dass Svetlana Aleksievičs dokumentarische Prosa das ursprüngliche Material faktualer Zeugenberichte etwa durch Auswahl und Komposition relevanter Passagen bis zu einem gewissen Grad literarisch formt, was für Faruk Šehićs Erfahrungen ebenso gilt, die er durch das Schreiben zu einem künstlerischen Narrativ ordnet. Umgekehrt bezieht sich der fiktionale Roman von Andrej Gelasimov auf Kriegserinnerungen und damit auf faktuale Quellen.

2 Im Folgenden verweise ich auf die Primärtexte mit den Siglen: A für Aleksievič 1991 und Aleksijewisch 2016 (dt.); G für Gelasimov 2011 und Gelassimow 2011 (dt.); Š für Šehić 2008; i verweist auf die online verfügbare russische Neuauflage von Aleksievič (2006). Die Auflagen von Cinkovye malčiki unterscheiden sich teilweise stark voneinander. Passagen, die in der deutschen Ausgabe nicht enthalten sind, wurden von mir übersetzt. 
Parallelen zwischen faktualen und fiktionalen Texten wurden bereits in anderen Zusammenhängen festgestellt: So erkennen etwa Kai Marcel Sicks und Sünne Juterczenka an einem Korpus faktualer und fiktionaler Rückkehrerzählungen eine gleichermaßen fiktionalisierend-ausschmückende Erzählung der Heimkehr (Sicks und Juterczenka 2011, 12). Interessanterweise gehen demgegenüber alle drei hier untersuchten Texte kaum auf die Heimkehr als Motiv ein, was auch insofern bemerkenswert ist, als sich das Ur-Narrativ des Kriegsheimkehrers - Homers Odyssee - völlig auf die Heimreise und das Ankommen des Helden konzentriert. Lediglich bei Aleksievič erwähnen manche der ehemaligen Soldaten kurz die Wahrnehmung der veränderten Umstände im Moment der Rückkehr - veränderte Beziehungssituationen und ein verändertes Lebensgefühl. Dass die Heimkehr an sich in den gewählten Texten nicht ausführlicher thematisiert wird, kann als programmatisch für das Scheitern der sozialen Wiedereingliederung verstanden werden, das stattdessen in den Skizzierungen der neuen Lebenssituation jeweils im Vordergrund steht. ${ }^{3}$

Die Ähnlichkeiten der im Folgenden behandelten Texte sind außerdem mit ihrer pazifistischen Grundhaltung und mit ihrem gesellschaftspolitischen Anliegen zu erklären, ein Bewusstsein für eine Randgruppe der Gesellschaft zu schaffen: Anders als die in Russland bis heute als siegreiche Helden inszenierten Soldaten des Zweiten Weltkrieges (des ,Großen Vaterländischen Krieges‘) werden ehemalige Kriegsteilnehmer aus Afghanistan, Tschetschenien und Jugoslawien öffentlich nur eingeschränkt thematisiert, da die entsprechenden Kriege sich aus unterschiedlichen Gründen nicht für ruhmvolle Inszenierungen eignen. $\mathrm{Zu}$ klar ist jeweils das Bewusstsein um Verluste sowie darüber, wie wenig durch die Kampfhandlungen erreicht wurde. Im Kontext von Afghanistan und Tschetschenien kommt dazu noch die nachträgliche Erkenntnis über Manipulation und Fehlinformationen, zumal diese Kriege von den politisch Verantwortlichen jeweils als humanitärer Einsatz dargestellt wurden (Welch 2003, 152).

Aleida Assmann reflektiert die Bedeutung individueller Erinnerungsnarrative für die historische Überlieferung wie folgt:

Erinnerung als verkörperte und geteilte Geschichtserfahrung ist an diesen grundlegenden Rhythmus der Generationen gebunden, der Geschichte im Gedächtnis der Gesellschaft so vielstimmig, komplex und strittig macht. Heterogene Perspektiven bestehen nebeneinander und fügen sich nicht zu einer gemeinsamen Geschichte, geschweige denn zu einer

3 Motive einer nur bedingt geglückten Heimkehr aus dem Krieg untersuchte für den sowjetischen Kontext bereits Olena Sivuda (2014, 127-137). Elisabeth Frenzel nennt zahlreiche Beispiele für Kriegsheimkehrer mit Anzeichen von Traumatisierung in der europäischen Literatur (1999, 336-339). 


\begin{abstract}
,master narrative‘. In totalitären Systemen ist die Koordination und Vereinheitlichung von Geschichte im sozialen Gedächtnis eine zentrale Aufgabe des Staates; diese Aufgabe setzt er bekanntlich durch Bildungsinstitutionen, historische Museen, Massenmedien und politische Rituale um. Unter solchen Umständen einer allgemeinen Ausrichtung auf eine verbindliche patriotische Version von Geschichte, wie dies etwa gegenwärtig in Russland der Fall ist, gewinnen individuelle Erinnerungen und Familiengeschichten den Status von Indizien einer ,Gegengeschichte‘, derer sich Dissidenten in Nichtregierungsorganisationen annehmen. (Assmann 2014, 181)
\end{abstract}

Unabhängig von den unterschiedlichen offiziellen Formungsbestrebungen in den staatlichen und gesellschaftlichen Erinnerungsdiskursen der drei nationalen Kontexte (Sowjetunion vs. Russland vs. Ex-Jugoslawien), thematisieren alle drei Werke eine ,von außen geformte' Geschichte, gegen die sie anschreiben, indem sie ihr eine oder mehrere persönlich perspektivierte ,Gegengeschichte(n)` entgegenstellen. Dieses verbindende Moment ist verantwortlich sowohl für die subjektive Darstellung faktualer Grundlagen als auch für die Vielschichtigkeit der in ihnen vorgestellten Opfer- und Täternarrative, die beständig ineinandergreifen und einander dadurch zugleich widerlegen. Es bildet außerdem jene Basis, auf der die gewählten Analysekategorien zugänglich werden, und weist Körperempfindungen, der Reflexion von Handlungsmotivationen, Identität und Zugehörigkeit sowie Gegenüberstellungen heterogener gesellschaftlicher Bewertungen von Kriegsheimkehrern ihren Platz in den Texten zu.

\title{
2 Kriegstrauma
}

In allen drei Texten sind Kriegstraumata zunächst indirekt sehr stark präsent, denn die Figuren tragen deutliche Anzeichen posttraumatischer Belastungsstörungen; selbstgewählte Isolation, Rückzug in den geschützten Bereich der Familie, Angstzustände, Hilflosigkeit und Alkoholmissbrauch prägen die Darstellungen. Allen drei Texten ist das Anliegen eingeschrieben, die öffentlich verschwiegenen tatsächlichen Lebensumstände ehemaliger Kriegsteilnehmer sowie deren psychische Verfassung zu thematisieren. Alle drei Texte schildern typische Symptome von Traumatisierung, die medizinisch als „prozedurale Überlebensprogramme“ beschrieben werden, die bei heftigen Emotionen in „Töten oder Getötetwerden (Kampf oder Flucht), in Kraftlosigkeit, Kollaps und Scham oder in ein Gefühl der Niederlage und Hilflosigkeit“ umschlagen (Levine 2015, 76).

Aus der Leere des posttraumatischen Alltags rekonstruiert Šehićs autobiografischer Text Schritt für Schritt die Innenperspektive symptomatischer Panikanfälle und nächtlicher Schlaflosigkeit, die sich aus der Angst vor Alpträumen speist: 
Bojao sam se spavanja, jer ništa nije moglo zaustaviti bujicu ratnih prizora, ni srce što preskače štekteći u ritmu kratkih rafala. Često bih skoćio iz kreveta sa hercom u grlu, upalio sve sijalice u stanu i otvorio prozore. $(\check{S}, 193)$

[Ich hatte Angst vor dem Einschlafen, denn nichts konnte die Flut an Kriegsvisionen aufhalten, oder vor dem Klopfen meines Herzens im Rhythmus schneller Salven. Oft sprang ich aus dem Bett, das Herz im Hals, schaltete alle in der Wohnung vorhandenen Glühbirnen ein und öffnete die Fenster.]

In Aleksievičs Zeugenberichten fällt das Fehlen psychischer Unterstützung für die Kriegsheimkehrer aus Afghanistan auf. Auch hier werden Alpträume beschrieben, wobei zugleich die Feststellung von Interesse ist, dass diese anstelle einer Verbesserung der psychischen Verfassung oft erst nach der Heimkehr verstärkt einsetzen:

Там сны о войне не видел. А здесь ночью воюю. Догоняю эту маленькую девочку... Глаза-маслины... Ручонка болтается, вот-вот отлетит... - Надо мне к психиатру? спросил у своих ребят. - Чего? - Воюю. - Мы все воюем. (А, 78)

In Afghanistan hab ich nachts nicht vom Krieg geträumt. Hier kämpfe ich jede Nacht. Ich renne hinter dem kleinen Mädchen her... die mandelförmigen Augen... Die Hand baumelt hin und her, gleich fällt sie ab. „Muss ich zum Psychiater?“, fragte ich ein paar Kumpels. „Warum?“ „Ich kämpfe im Traum immer wie ein Wilder.“ „Das geht uns genauso.“ (A, 117)

Andrej Gelasimov thematisiert ebenfalls die mit dem Schlaf verbundene Angst. Als sein Protagonist Kostja nach einem Granatenangriff auf seinen Panzer schwer verletzt in einem Lazarett liegt, fürchtet er sich vor seinen Träumen. Aufgrund der Bandagen auf dem verbrannten Gesicht ist er noch stärker von der Außenwelt abgeschnitten und die unverarbeiteten Eindrücke der Vergangenheit erlangen quälende Präsenz:

Но самым страшным в госпитале были сны. Потому что первое время, после того как очнулся, я не помнил, что с нами произошло. Как отрезало. Забыл даже, как в бэтээр садились. Лежал в бинтах, стонал и ничего не помнил. Больно было, поэтому просто ждал медсестру. А у нее прохладные руки. [...] Кто-то говорил - промедол. И еще говорили: Зачем ты ему набираешь так много? [...] И ее голос. Ты знаешь, как ему больно? Пусть немного поспит. [...] Потом я начал видеть сны и стал бояться ее приходов. Потому что я стал вспоминать. Я все увидел во сне. (G, 277-278)

Das Schlimmste im Lazarett aber waren die Träume. In der ersten Zeit, nachdem ich wieder zu mir gekommen war, hatte ich mich nicht daran erinnert, was mit uns passiert war. Wie abgeschnitten. Ich hatte sogar vergessen, wie wir in den Panzer gestiegen waren. Ich lag da in meinen Bandagen, stöhnte und konnte mich an nichts erinnern. Ich hatte Schmerzen und wartete deshalb immer nur auf die Schwester. Sie hatte kühle Hände. [...] Jemand sagte: 
- Pramidol. Und jemand anders sagte: - Warum gibst du ihm so viel? [...] Ihre Stimme: Weißt du, was für Schmerzen er hat? Lass ihn noch etwas schlafen. [...] Später fingen die Träume an, und ich begann sie zu fürchten. Weil ich mich erinnerte. Ich sah alles im Traum. $(G, 73)$

Wie die weiteren Schilderungen verdeutlichen, ist die psychische Belastung langfristig schwerer zu ertragen als die physischen Schmerzen. Die Grenzerfahrungen des Krieges werden jedoch auch darin deutlich, dass die verwundeten Soldaten in ihrer Verletzlichkeit ähnlich empfinden wie Kinder. Gelasimov überblendet Kostjas Erwachen im Lazarett mit einem Trauma aus dessen Kindheit: mit der Erinnerung an die Untreue seines Vaters, die mit dem physischen Schmerz einer etwa zeitgleich durchgeführten Blinddarmoperation assoziiert ist. Körperliche und seelische Verletzungen werden dadurch besonders stark in ihrer wechselseitigen Verwobenheit deutlich und umspannen als assoziatives Netz fast alle Lebensbereiche. Aleksievičs Aufzeichnungen lassen die Verletzlichkeit in ähnlicher Form erkennen, denn auch hier gelten die primären Bedürfnisse der Verwundeten mütterlicher Zuwendung und Nähe: „Они кричали всегда: „Мама!“ Когда болит... И страшно... Других имен я не слышала...“ (А, 21) [„,Die Jungs haben immer ,Mama!' geschrien, wenn’s zu schlimm war, wenn die Schmerzen zu groß waren. Andere Namen hab ich nicht gehört“ (A, 42)].

Šehić lässt am Ende seines Texts das traumatische Erleben die Überhand gewinnen. Die Vorfreude auf das Finale der Fußball-Champions-League wird durch eine apokalyptische Kriegsvision überlagert; und anders als die Erwartung des Sportevents annehmen lässt, endet Šehićs Text mit der imaginierten Auslöschung des erzählenden Individuums:

\footnotetext{
Sutra naveče je Liga šampiona. [...]

Apokalipsa će doći u obliku fotonskog torpeda. Bez najave, masovnih scena patnje, Drugog dolaska, zvijeri, vrisaka i ceremonija. Ona će doći iz svih pravaca i zabiti se u jednu sićušnu tačku. Moje srce. (̌̌, 193)

[Morgen Abend ist Champions League. [...]

Die Apokalypse wird in Form eines Photonentorpedos eintreffen. Ohne Vorwarnung, Massenunruhen, Zweite Ankunft, Ungeheuer, Schreie und Zeremonien. Sie wird aus allen Richtungen gleichzeitig kommen und in eine Zielscheibe treffen. Mein Herz.]
}

Eine solche performative Präsenz des Traumas, die am Ende des Texts gewissermaßen die Tilgung des zuvor Erzählten bedeutet, ist kein bloßer literarischer Effekt, sondern beschreibt die Realitätswahrnehmung traumatisierter Menschen, die den diagnostischen Merkmalen einer posttraumatischen Belastungsstörung in der Internationalen Klassifikation psychischer Störungen (ICD-10) entspricht: u.a. sind hier Amnesie, eingeschränkte Aufnahmefähigkeit, veränderte Realitäts- 
wahrnehmung, Rückzug, vegetative Anzeichen panischer Angst und Flashbacks angeführt (WHO 2015, 206-207). Gelasimov und Šehić beschreiben das Lebensgefühl nach dem Krieg als mechanische Fortsetzung eines geregelten Alltags, in dem die inneren Verletzungen aufgrund der Routine kaum nach außen dringen.

Die von Aleksievič interviewten Kriegsheimkehrer lassen die psychophysische Verfassung von Kriegstraumatisierten als jenen aus der Traumaforschung bekannten Schwebezustand zwischen unauslöschlichen Schreckensbildern, Amnesie und unberechenbaren traumatischen Erinnerungsschüben erkennen. Während viele Interviewpartner über Flashbacks klagen, beschreiben andere die erlebten Kriegsereignisse als wie durch einen Schleier verborgen, unwirklich oder auch unzugänglich:

\footnotetext{
Что-то с памятью... Даже думаю уйти со второго курса института... От меня куда-то убегают, исчезают человеческие лица, слова. Собственные ощущения... Остаются отрывки, осколки... Как будто со мной не было того, что было... (А, 109-110)
}

Irgendwas stimmt mit meinem Gedächtnis nicht mehr. Ich habe schon überlegt, das zweite Studienjahr abzubrechen. Die Gesichter verschwimmen, Worte... die eigenen Wahrnehmungen... Was bleibt, sind nur Bruchstücke, Splitter... als hätte das alles nicht ich erlebt. $(\mathrm{A}, 160)$

Hier und in anderen Berichten betrifft die gedämpfte Realitätserfahrung nicht nur die traumatische Vergangenheit, sondern auch die Gegenwart. Die zuvor zitierte Schilderung von Aleksievičs Interviewpartner bricht bei einem Ereignis nach dem Krieg ab, als ein Jagdkollege eine Gans tötet und der Erzähler feststellt, dass er nicht mehr töten will.

Bei vielen Interviewten hat die Grenzerfahrung des Krieges so tiefe Spuren hinterlassen, dass sich die Alltagserfahrung entscheidend verändert hat. Zugleich werden häufig Bemühungen thematisiert, diese innere Veränderung nach außen hin zu verbergen. Was hinter dieser ruhigen Fassade vor sich geht, beschreibt einer von Aleksievičs Gesprächspartnern, der an sich selbst die ständige Alarmbereitschaft seines Körpers feststellt; gleichsam als physische Notreaktion werden gewisse angstauslösende Alltagssituationen vermieden, da sie für Unbeteiligte unvorhersehbare, gewaltsame Schutzreflexe auszulösen drohen:

В моей комнате те же книги, фото, магнитофон, гитара. Только меня того ...Нет... Через парк пройти не могу - оглядываюсь. В кафе официант станет за спиной: „Заказывайте“. А я готов вскочить и убежать, не могу, чтобы у меня кто-то за спиной стоял. Увидишь подонка, одна мысль: „Расстрелять его надо.“ (А, 113)

In meinem Zimmer ist alles wie vorher: die Bücher, die Fotos, der Kassettenrecorder, die Gitarre. Aber ich bin ein anderer. Durch einen Park kann ich nicht gehen, ohne mich ständig 
umzugucken. Wenn im Café der Kellner hinter mir steht und sagt: „Was wünschen Sie?“, möchte ich am liebsten aufspringen und rausrennen, ich ertrag's nicht, wenn jemand in meinem Rücken steht. Wenn du einen Schuft siehst, hast du nur einen Gedanken: Erschießen! (A, 165 und 246)

Diese Passage aus Cinkovye mal'čiki wurde außerdem am 15. Februar 1990 - ohne Namensnennung - in der Komsomol'skaja Pravda veröffentlicht. Der ehemalige Soldat Taras Kecmur zitiert sie in seiner Klage, die eine der Grundlagen für den Gerichtsprozess gegen Svetlana Aleksievič am 29. November 1993 bildete und schließlich auch den Ausschlag für die Verurteilung der Autorin gab. Während unverständlich bleibt, dass ein anonymisierter Zeugenbericht von dessen Urheber als Ehrenverletzung beanstandet wird, verdeutlicht der gerade darauf basierende Urteilsspruch, dass neben Berichten über Angst, unwürdige Lebensumstände und die Verrohung von Menschen im Krieg sichtlich auch Kriegstraumata ein tabuisiertes Thema darstellen. Für den öffentlichen Diskurs bedeutet das Verschweigen von Traumatisierung eine Ablehnung der Opferrolle, die damit zusammenzuhängen scheint, dass im Falle dieser Traumata die Täterrolle dem Staat zukommen würde.

Aleksievič stellt ihrer Sammlung als Prolog den Bericht einer Mutter voran, deren Sohn nach seiner Heimkehr aus Afghanistan einen Menschen getötet hat: „Он убил человека моим кухонным топориком... А утром принес и положил его в шкафчик... Как обыкновенную ложку или вилку...“ (А, i) [„,Er hat einen Menschen getötet, mit meinem Küchenbeil... Und am Morgen hat er es zurückgebracht und wieder in den Schrank gelegt. Wie einen ganz normalen Löffel oder eine Gabel...“ (A, 15)].

Wie bereits Taras Kecmurs Schilderung, zeigt auch diese tragische Episode, dass Kriegstraumata neben der Belastung für Betroffene und Angehörige eine massive gesellschaftliche Gefahr darstellen, da die Traumatisierung zu psychotischen Zuständen führen kann, in denen die Reflexe der Kriegsrealität erneut wirksam werden.

\section{Kriegsidentität}

Sowohl während als auch nach dem Krieg wird bei den Kriegsteilnehmern eine eigene Kriegsidentität erkennbar, die zwischen Angst und Gefühlslosigkeit und somit zwischen Opfer- und Täteridentität verortbar erscheint. Während Angst auf Grenzerfahrung, Zwang und Unfreiwilligkeit hindeutet und damit auf typische Charakteristika eines Opfers verweist, bedeutet Gefühlsunzugänglichkeit in den folgenden Beispielen Bindungslosigkeit selbst im engsten Kreis der Familie sowie 
Isolationsbedürfnis und innere Vereinsamung. Besonders im Zusammenhang mit traumatisch bedingten Flashbacks begünstigt dieser Zustand eine unberechenbare latente Neigung zu aggressiven Handlungen während psychotischer Episoden.

Im Folgenden wird zunächst darauf eingegangen, wie das Analysematerial die Manipulation des Selbstempfindens in Kriegskontexten darstellt, wobei zum einen die Verinnerlichung von Glaubenssätzen und zum anderen bewusstseinsverändernde Substanzen eine Rolle spielen. Danach wird eine weitere Erkenntnis aufgezeigt, die sich aus den Texten ergibt: Die im Krieg internalisierte Bewusstseinsveränderung bleibt nach dem Krieg latent als langfristige Anfälligkeit für psychotische Zustände bestehen, bei denen die im Krieg erlernten Reflexe wirksam werden.

Wie Šehić schreibt, sind die Rollen im Krieg klar definiert, wobei plakativ zwischen Kameraden und Gegnern differenziert wird, um auf dieser Basis unhinterfragt das Angriffsverhalten zu steuern: „Strategija naše komande je gladila: oni nemaju motiva za ratovanje, mi imamo“ (ك̌, 96) [Die Strategie unseres Kommandos sah wie folgt aus: Sie haben kein Motiv zu kämpfen, wir schon].

Zugleich reduzieren während des Krieges soziale Einflüsse und Drogenmissbrauch das eigenständige Denken, sodass das Kriegsmotiv neben dem Glauben an die gerechte Handlung auch durch die Gruppendynamik aufrechterhalten wird. Durch das Kollektiv schwindet das Täterbewusstsein, welches Einzelpersonen vor dem Töten zurückschrecken lässt: „Сегодня один мальчик [...] рассказывал, как непривычно и в то же время азартно убивать вместе. И как страшно расстреливать“ (А, i) [„,Heute erzählte mir ein Junge [...], wie ungewohnt und zugleich aufregend es sei, gemeinsam zu töten. Und wie schrecklich, jemanden zu erschießen“ (A, 26-27)].

Šehić erwähnt, dass die Uniform die Selbstwahrnehmung als Individuum reduziert und zugleich auch die Angst vor dem Gegner abmildert: „Ponekad, čovjek pomisli da je u maskiranoj uniformi nevidljiv i, samim tim, neuništiv“ (Š, 87) [Maskiert durch die Uniform hält sich der Mensch manchmal für unsichtbar und für unverletzlich].

Besonders Šehić und Aleksievič gehen außerdem auf bewusstseinserweiternde Substanzen wie Drogen und Medikamente ein, die im Krieg eingesetzt werden, um den Soldaten das Töten zu erleichtern:

Многие курили. Анашу, марихуану... Кто что достанет... Объясняли, что становишься сильным, свободным от всего. В первую очередь от своего тела. Как будто ты на цыпочках идешь, слышишь легкость в каждой клеточке, чувствуешь каждый мускул. Хочется летать. Как будто летишь! Радость неудержимая. Все нравится, смеешься над всякой ерундой. Слышишь лучше, видишь лучше. Различаешь больше запахов, больше звуков. В этом состоянии легче убивать - ты обезболился. Жалости нет. Легко умирать - страх уходит. (А, 24) 
Viele haben Haschisch oder Marihuana geraucht, was jeder kriegen konnte. Du fühlst dich stark und frei danach. Frei vom eigenen Körper. Du gehst wie auf Zehenspitzen, spürst jeden Muskel. Du möchtest am liebsten fliegen. Du schwebst fast. Und dann die unbändige Freude! Dir gefällt alles. Du lachst über jeden Mist. Du hörst besser, siehst besser. Unterscheidest mehr Gerüche, mehr Geräusche... In diesem Zustand fällt das Töten leicht. Du bist betäubt, $\mathrm{du}$ hast kein Mitleid. Es stirbt sich leicht in diesem Zustand. Die Angst schwindet. Du hast das Gefühl, als hättest du eine kugelsichere Weste an, als wärst du ganz gepanzert. (A, 47)

Auch die stimmungsaufhellende Wirkung der Drogen ist dabei relevant, denn zahlreiche Kriegsteilnehmer klagen über Depressionen. Auch diese bedingen eine veränderte Wahrnehmung, wobei jedoch Hypervigilanz und psychotische Zustände hier mit Angst und Selbstverlust verbunden sind. Neben ihrer leistungssteigernden Wirkung werden Medikamente daher auch gegen nervöse Zustände sowie als Beruhigungsmittel verwendet, wobei dieser Einsatz leicht außer Kontrolle gerät, da eine hohe Dosierung die einzige schnelle und wirksame Hilfe gegen Symptome verspricht, jedoch keine langfristige Heilung in Aussicht stellt:

Nisam mogo kontrolisati tok vlastitih misli. Sluh mi se pojačo do maksimuma. Mislio sam da drugi ljudi mogu čuti moje misli. Odlučio sam otići kod brigadnog doktora i tražiti uputnicu neuropsihijatru. [...] Pogledao sam u papir. Kontrola za dvadeset jedan dan i terapija tabletama [...]. Dvadeset jedan dan odmora! Ma kakav odmor, biće to čisto ubijanje, cugom i ostalim pomoćnim sredstvima. Život punim gasom. (ک̌, 101)

[Ich war meiner Gedanken nicht mehr Herr. Mein Gehörsinn war bis zu einem Maximum geschärft. Ich hatte das Gefühl, andere Menschen könnten meine Gedanken hören. So entschied ich mich, den Feldarzt aufzusuchen und mich zum Neuropsychiater überweisen zu lassen. [...] Ich blickte auf den Zettel. Einundzwanzig Tage unter Beobachtung und Medikamententherapie [...]. Einundzwanzig Tage Erholung! Aber was für eine Erholung, das wird eine reine Abtötung, durch Saufen und andere helfende Mittel. Ein Leben mit Vollgas.]

Šehićs Darstellung verdeutlicht, dass sich ein gewisser Kriegsalltag einstellt, der nach anderen Prinzipien funktioniert als der gewöhnliche Alltag. Angst- und Schmerzfreiheit haben Priorität; aus Sicht der Kriegsteilnehmer gilt es, kurzfristig die Belastung zu reduzieren, aus Sicht der Kriegsführenden, die Einsatzfähigkeit wiederherzustellen. Niemand der Beteiligten denkt dabei an Langzeitfolgen und es fällt sogar schwer, sich ein Leben nach dem Krieg vorzustellen:

- Šta čete raditi ako preživite rat? - Ješću i piću do besvijesti. Trudiću se da živim. Malo me strah mira. Teško mi je zamisliti ostatak svijeta, u kojem se ne ratuje. To mi djeluje skoro fantastično. $(\check{S}, 101)$

[- Was werden Sie machen, wenn Sie den Krieg überleben? - Ich werde essen und trinken, bis ich ohnmächtig werde. Ich werde mich bemühen zu leben. Ich habe ein bisschen Angst vor dem Frieden. Es fällt mir schwer, mir eine Welt vorzustellen, in der nicht gekämpft wird.] 
Der an die Stelle des Alltags tretende permanente Ausnahmezustand, in dem es um das psychische und physische Überleben geht, drängt Opfer- und Täterdiskurse sichtlich in den Hintergrund. Dasselbe gilt für die individuelle Identität, da das Individuum zum einen durch Uniform und Befehlsgehorsam als Teil einer Masse agiert und zum anderen durch Medikamentenmissbrauch in Distanz zu seinen sinnlichen und emotionalen Empfindungen tritt. Dass Šehićs autobiografisches Ich sich trotz seines schlechten Zustands so vollständig an den Krieg gewöhnt hat, dass es sich nicht in eine Realität des Friedens zurückwünscht, zeigt eine zumindest unbewusste Ahnung der durch Kriegshandlungen und Kriegsfolgen bewirkten Identitätsveränderung.

Gerade auch Taras Kecmur schildert in einer weiteren seiner später beanstandeten Passagen, dass er nach seiner Heimkehr in die Sowjetunion den Wunsch verspürte, wieder nach Afghanistan in den Krieg zurückzureisen, um weiterzukämpfen: ${ }^{4}$ „Ходил в военкомат, просился назад, не взяли. Война скоро кончится, вернутся такие же, как и я. Нас будет больше“ (A, 113) [„Ich war beim Wehrkreiskommando, ich hab gebeten, mich nach Afghanistan zurückzuschicken. Sie haben es abgelehnt. ,Der Krieg ist bald zu Ende.' Den jetzigen Heimkehrern wird es genauso gehen wie mir. Wir werden noch mehr werden“ (A, 246-247)].

Angesichts dessen, dass Kecmurs Bericht sehr schmerzhafte und erschreckende Erfahrungen schildert und sogar direkte Kritik an der sowjetischen Politik und der Entscheidung für diesen Kriegseinsatz übt, ist der plötzliche Wunsch, an den Kriegsschauplatz zurückzukehren, erstaunlich. Zugleich verdeutlicht er die Schwierigkeit, sich wieder in die Gesellschaft einzugliedern, nachdem Werte, Handlungsnormen und Realitätserfahrung so deutlich umgekehrt wurden. Viele der Heimkehrer leiden nicht nur an den ihnen zugefügten Verletzungen und Verlusten, sondern außerdem an einem Tätertrauma und fühlen sich innerlich gespalten: „На войне приходилось делать прямо противоположное тому, чему нас учили в мирной жизни, а в мирной жизни надо было забыть все навыки, приобретенные на войне (А, i)“ [„,Im Krieg mussten wir genau das Gegenteil von dem tun, was man uns in Friedenszeiten beigebracht hatte. Und

\footnotetext{
4 Svenja Goltermann behandelt Narrative historischer Quellen aus dem Zweiten Weltkrieg, wo zahlreiche Beispiele traumatisierter Soldaten vorliegen, die sich nach der Rückkehr in einem Zwischenraum zwischen Krieg und Neuanfang gefangen fühlen und nicht in den Alltag zurückfinden (2011, 145-161). Wie Steffi Bahro aufzeigt, gibt es bereits in Märchen typische Narrative, in denen die Heimkehr von Soldaten scheitert und die Figuren ihre Heimat aus unterschiedlichen Gründen gleich wieder verlassen $(2011,118)$.
} 
in Friedenszeiten sollten wir alles vergessen, was wir uns im Krieg angeeignet haben“ (A, 246)].

Sowohl Šehić als auch Aleksievič und viele ihrer Interviewpartner machen mit ihren kritischen Darstellungen der Kriegsrealität sowie dort verübter Handlungen dennoch auch die Opferrolle der Soldaten sichtbar, die nicht auf deren Schuldlosigkeit, sondern auf dem Machtmissbrauch durch höhere Instanzen und der Transformation von Individuen in Humanressourcen basiert: „Вы, пожалуйста, никогда не трогайте этого, много сейчас умников здесь, почему же никто не положил партбилет, никто пулю себе в лоб не пустил, когда мы были там...“ (А, i) [„Bitte rühren Sie dieses Thema niemals an, hier gibt es heute viele Schlaumeier. Aber warum hat keiner sein Parteibuch hingeschmissen? Warum hat sich keiner eine Kugel in den Kopf gejagt, als wir dort waren?“ $(\mathrm{A}, 246)]$.

Die Kriegsidentität betrifft keineswegs nur das veränderte Fühlen und Handeln im Krieg, sondern besonders auch deren Nachwirkungen, wie das Gefühl gesellschaftlicher Nicht-Zugehörigkeit nach Extremsituationen. Marginalisierung geschieht dabei sowohl durch direkte Ablehnung als auch aufgrund von Rückzug als Reaktion auf diese Entfremdungserfahrung:

Нас зовут „афганцами“. Чужое имя. Как знак. Метка. Мы не такие, как все. Другие. Какие? Я не знаю, кто я: герой или дурак, на которого надо пальцем показывать? А может, преступник? (А, 18)

Man nennt uns „die Afghanen“. Ein fremder Name. Wie eine Kennzeichnung. Das ist wie ein Brandmal. Wir sind nicht so wie die anderen. Aber was sind wir? Was bin ich? Bin ich ein Held oder ein Dummkopf, auf den man mit dem Finger zeigt? Bin ich vielleicht sogar ein Krimineller? (A, 38)

Erschwerend für das Zurückfinden in eine zivile Identität ist außerdem die unklare offizielle Position ehemaliger Kriegsteilnehmer. Versuche, den Heldenmythos der Vaterlandsverteidiger aus dem Zweiten Weltkrieg auch um andere russische Soldaten aufzubauen, scheitern daran, dass diese sich nicht als Verteidiger fühlen, da sie sich ihrer Rolle als Aggressoren bewusst sind. Zudem hinterfragen sie Gewaltexzesse kritisch und auch die eigene Traumatisierung steht $\mathrm{zu}$ dem ihnen zugeschriebenen Heldentum in krassem Widerspruch:

Приглашают выступать в школы. А что рассказывать? О боевых действиях... [...] 0 том, как я до сих пор боюсь темноты, что-нибудь упадет - вздрагиваю? Как брали пленных, но до полка не доводили... [...] О коллекциях засушенных человеческих ушей? [...] Об этом, что ли, хотят услышать в наших школах? Нет, там нужны герои. $(\mathrm{A}, 18)$ 
Wir sollen in Schulen auftreten. Aber was sollen wir da erzählen? Von Kampfhandlungen? Davon, dass ich immer noch Angst vor der Dunkelheit habe, dass ich zusammenfahre, sobald was runterfällt? Wie Gefangene gemacht wurden, die nicht bis zum Regiment kamen? Von Sammlungen getrockneter Menschenohren als Trophäen? [...] Will man das in Schulen hören? Nein, wir brauchen Helden! (A, 39)

Bereits während des Afghanistan-Krieges wurde den dort Stationierten die realitätsverzerrende Dimension der Medienberichte in ihrer sowjetischen Heimat bewusst. Viele von ihnen hatten sich nicht freiwillig gemeldet, sondern waren uninformiert dorthin befördert worden (A, 26-27). Propagandaplakate und Zeitungsberichte wurden auch in den Kriegsgebieten verbreitet, wo die Diskrepanz zwischen diesen und der erlebten Wirklichkeit offenkundig war:

Скоро начали понемногу задумываться: кто же мы? Наши сомнения начальству не понравились. Тапочек, пижам еще не было, а уже развешивали привезенные лозунги, призывы, плакаты. На фоне лозунгов - худые, печальные лица наших ребят. (А, 22)

Wir haben dort, in Afghanistan, angefangen darüber nachzudenken, wer wir eigentlich sind. Man zerstreute unsere Zweifel. Keine Hausschuhe und Schlafanzüge - aber Losungen, Aufrufe und Plakate, die wurden ausgehängt! Und dazu die schmalen, traurigen Gesichter unserer Soldaten. Die vergess ich nicht! $(\mathrm{A}, 43)$

In der Heimat hingegen bewirkten diese Fehlinformationen, dass sich Menschen mit völlig falschen Vorstellungen freiwillig zum Kriegseinsatz meldeten:

Как раз в это время в „Правде“ напечатали очерк „Афганские мадонны“. Из Союза девочки писали: он всем понравился, некоторые даже пошли в военкомат проситься в Афганистан. [...] А мы не могли спокойно пройти мимо солдат, те ржали: „Бочкаревки, вы, оказывается, героини?! Выполняете интернациональный долг в кровати!“ $(\mathrm{A}, 65)$

Damals erschien in der Prawda gerade der Artikel über die „Afghanischen Madonnen“. Aus der UdSSR schrieben Mädchen begeisterte Briefe, einige haben sich sogar im Wehrkreiskommando gemeldet, wollten freiwillig nach Afghanistan gehen. Und wir kamen an keinem Soldaten vorbei, ohne angemacht zu werden. „Na, ihr Offiziersmatratzen? Na, ihr Heldinnen? Erfüllt ihr eure internationalistische Pflicht im Bett?“ (A, 101)

Dass Frauen im Krieg als Prostituierte missbraucht und dafür geächtet wurden, beschreibt ebenfalls eine Form des Identitätsverlusts während, doch noch verstärkt nach dem Krieg. Die Lage solcher Frauen wird gesellschaftlich noch weniger thematisiert, weil sie mit Scham behaftet und dadurch tabuisiert ist. Man kann hier von stummen Opfern sprechen, die sich noch schwerer öffentlich zu Traumatisierung und Identitätsverlust bekennen können als ehemalige Soldaten, 
da ihre körperlichen und seelischen Verletzungen nicht auf Kriegshandlungen zurückzuführen sind.

Direkt damit in Verbindung steht auch die andere Seite, jene der Soldaten, von denen einige durch die extremen Erlebnisse im Krieg ihre emotionale Sensibilität verlieren und sich zugleich ein Sexualverhalten aneignen, das hauptsächlich der Beruhigung gilt und dabei hilft, mit psychotischen Angststörungen fertig zu werden. Wie Faruk Šehić beschreibt, bleibt diese veränderte Wahrnehmung - gemeinsam mit den Ängsten - mitunter auch nach dem Krieg erhalten:

Zaljubio se u ženu sa jumbo plakata. [...] Glava mi se okreće kao ventilator da bih pohvatao sve te guzove \& sise \& drčne face sa slatkim okicama. Stvarno sam jedan perverzni tridesettrogodišnjak, sram me i stid bilo. (̌̌, 152)

[Ich verliebte mich in die Frau von einem Jumbo-Plakat. [...] Wie ein Ventilator verdrehte ich den Kopf, um alle Hintern \& Brüste \& trotzigen Fratzen mit den süßen Äuglein zu erspähen. Ich bin wirklich ein perverser Dreiunddreißigjähriger, Scham und Schande über mich.]

An Šehićs Text fällt außerdem eine besondere Häufigkeit sexueller Handlungen auf, die ebenfalls ihren Platz unter mentalen und physischen Strategien der Beruhigung einnehmen.

Als Herausforderung beschreiben ehemalige Kriegsteilnehmer jedoch auch den zwischenmenschlichen Aspekt von Liebesbeziehungen. Einer von Aleksievičs Gesprächspartnern beschreibt seine Beziehung zu Frau und Tochter als tägliche harte Arbeit. Da seine Bemühungen, Liebe für sie zu empfinden, erfolglos bleiben, plagen ihn ein schlechtes Gewissen und ein Gefühl der Sinnlosigkeit:

\footnotetext{
Любовь... Категория не земная... Я не могу сказать, что я люблю. Сейчас я уже женат, у меня есть маленькая дочь, но я не знаю, что это - любовь или что-то другое, хотя я за них горло перегрызу, в асфальт вкопаю. Жизнь отдам!! Но что такое любовь? Люди признаются, что они любят, так они себе это представляют, но любовь - это дикая, кровавая и ежедневная работа. $(\mathrm{A}, \mathrm{i})$

[Liebe... Eine Kategorie nicht von dieser Welt... Ich kann nicht sagen, dass ich liebe. Jetzt bin ich schon verheiratet, habe eine kleine Tochter, aber ich weiß nicht, ob das Liebe ist oder etwas anderes, obwohl ich für sie die Kehle durchbeißen und im Asphalt vergraben würde. Ich gebe mein Leben!! Was ist Liebe? Menschen gestehen ihre Liebe, so stellen sie es sich vor, aber Liebe, das ist eine harte, blutige, tagtägliche Arbeit.]
}

Ein weiterer Afghanistan-Heimkehrer beschreibt ebenfalls seine nach dem Krieg abgestumpften Gefühle, die ihn zu dem Entschluss veranlassen, das Mädchen, in das er vor seiner Abreise verliebt war, nicht über seine Rückkehr zu informieren. Als sie ihn von sich aus aufsucht, bereit, ihm bei der Verarbeitung der Kriegser- 
fahrung beizustehen, konfrontiert ihn diese Begegnung mit seiner Entfremdung und dem Wunsch, sie zurückzuweisen:

Я встречался до армии с девушкой, был влюблен. Приехал и не позвонил ей. Она случайно узнала, что я уже в городе, нашла меня. Зря искала... Не надо было встречаться... „Того человека, которого ты любила, и он тебя любил - нет, - сказал я ей. - Я - другой. Ну, другой я!“. Она плакала. (A, i)

[Vor der Armee hatte ich eine Freundin und war verliebt. Als ich heimkehrte, rief ich sie nicht an. Sie erfuhr zufällig, dass ich schon in der Stadt bin und kam zu mir. Sie hat mich umsonst gesucht... Es wäre besser gewesen, wir hätten uns nicht getroffen... „Den Menschen, den du geliebt hast und der dich liebte, gibt es nicht mehr“, sagte ich zu ihr. „Ich bin ein anderer. Also, ich bin anders.“ Sie weinte.]

Nicht nur traumatisch bedingte Gefühlsunzugänglichkeit und Beziehungsunfähigkeit sind ausschlaggebend für den Identitätsverlust im Sinne einer zwischenmenschlichen Verankerung des Selbst. Als besonders schlimm werden nämlich auch Trennungen beschrieben, wenn die in der Heimat zurückgebliebene Freundin während oder nach dem Krieg eine Beziehung beendet hat (A, 46). Zusätzlich zu der Verunsicherung gerät dadurch auch die Soldatenidentität ins Wanken, die anhand der Rolle des starken Verteidigers von Heimat und Partnerin aufgebaut wurde. Dass Beziehungen aufgrund der Kriegsteilnahme beendet werden, führt also zu einem Widerspruch, der das Weltbild der Betroffenen erschüttert:

Девушка меня ждала: „Ну - думаю, - завалю в первый день... В первый день трахну...“ А она руку мою убирает с плеча: „Она вся у тебя в крови.“ Так либидо мне и отрезала на три года, три года я боялся к женщине подойти. Ё-мое! Нас же воспитывали: ты должен родину защищать, девушку свою защищать... Ты - мужчина... (А, і)

[Meine Freundin wartete auf mich: „Also - denke ich - am ersten Tag lege ich sie flach... Am ersten Tag fick ich sie...“ Doch sie nahm meine Hand von ihrer Schulter: „Sie ist voll Blut.“ Meine Libido war danach drei Jahre lang verschwunden, drei Jahre lang hatte ich Angst, mich einer Frau zu nähern. Verdammt! Uns haben sie doch beigebracht: Du musst deine Heimat verteidigen, deine Freundin beschützen... Du bist ein Mann.]

Wie die Beispiele unterschiedlicher Interviewpartner Aleksievičs zeigen, führen sowohl eine gefühlte innere Veränderung als auch die Distanzierung Nahestehender zur Isolation ehemaliger Kriegsteilnehmer. Beide Aspekte kommen auch in Andrej Gelasimovs Novelle auf mehreren Ebenen zum Tragen. Besonders deutlich werden sie an dem Protagonisten, der wegen seines durch Verbrennungen entstellten Gesichts die Gesellschaft meidet und aus demselben Grund auch umgekehrt in vielen Fällen von anderen gemieden wird; neben dem Rückzug in 
die eigene Wohnung und exzessivem Alkoholkonsum reduziert er in der Arbeit den Kontakt zu anderen Menschen auf das Nötigste: „Удивлялись, правда, когда я им говорил по телефону, что работаю один, но потом при встрече больше не удивлялись“ (G, 226) [,,Sie wunderten sich zwar, wenn ich ihnen am Telefon erklärte, dass ich allein arbeite, doch wenn sie mich dann sahen, wunderten sie sich nicht mehr“ $(G, 16)]$.

Die selbstgewählte Distanz zu Menschen wird jedoch von außen bestätigt, wenn unterschiedliche Menschen vor dem Anblick des verbrannten Gesichts zurückschrecken. Dies gilt nicht nur für Klienten, sondern etwa auch für einen Polizisten, womit der unprofessionelle und unsensible Umgang mit Kriegsversehrten durch die offiziellen Behörden kritisiert wird: „Но мы с ними и не дрались. Просто этот маленький мент сказал, что с моей рожей не по вокзалам ездить, а дома сидеть. Чтобы пассажиры не пугались“ (G, 287) [„,Aber wir hatten uns nicht geprügelt. Dieser kleine Bulle hatte nur gesagt, mit meiner Visage sollte ich nicht auf dem Bahnhof rumhängen, sondern besser zu Hause bleiben. Um die Passagiere nicht zu erschrecken“ (G, 83-84)].

Im Handlungsverlauf erlangt Kostja Eigenständigkeit und Selbstwertgefühl zurück. Er wird zum verstehenden Beobachter der Gesellschaft, womit Gelasimov der von außen festgeschriebenen Kriegsidentität eine weitere Ebene von Identität - ein inneres, frei wählbares Selbstgefühl - gegenüberstellt, die es seiner Figur ermöglicht, ihr Kriegstrauma zu überwinden und sich gesellschaftlich neu zu verankern.

Ein weiteres Thema bilden innergesellschaftliche Subgruppen. Der Protagonist und andere aus Tschetschenien Heimgekehrte bilden ein von der Gesellschaft abgegrenztes soziales Gefüge, das Kameradschaften pflegt, obwohl zugleich auch Feindschaften bestehen. Gelasimov thematisiert kollektive Identität dabei außerdem als strenge Abgrenzung zwischen Gruppen von Kriegsakteuren in unterschiedlichen Funktionen und im Kontext unterschiedlicher Kriege. Dazu zählt auch die Figur von Kostjas Vater, der ungeachtet seines Offiziersranges noch nie an einem Krieg teilgenommen hat, wofür ihn dessen Freunde mit Verachtung strafen:

- А вы сами в каком звании? - Подполковник. - Круто! Воевали уже? Горячие точки? Афганистан? Отец посмотрел на Генку, и глаза у него чуть сузились. - Нет, не пришлось. Я занимаюсь кадровой работой. (G, 254)

- Welchen Dienstrang haben Sie denn? - Oberstleutnant. - Stark! Haben Sie gekämpft? Hot Spots? Afghanistan? Mein Vater sah Genka an, und seine Augen verengten sich leicht. Nein, dazu hatte ich noch keine Gelegenheit. Ich leiste Kaderarbeit. (G, 47-48)

Allerdings verbindet Gelasimov die abschätzigen Bewertungen aufgrund von physischer oder psychischer Verfassung und biografischen Begebenheiten mit 
Kritik an menschlicher Oberflächlichkeit. Intolerantem Verhalten stellt er indirekt - Beispiele aus Alltagskontexten entgegen, indem er etwa eine Mutter beschreibt, die ihre Kinder am Fußballplatz wegen deren Kleidung zurechtweist:

- Ну как вы оделись? - шептала их мама. [...] - Теперь все подумают, что вам надеть нечего. Я же оставила все на кресле. [...] Я слушал их, стараясь, чтобы они не обращали на меня внимания, и думал о том, какие бывают дети. (G, 266-267)

Wie seht ihr denn aus? flüsterte ihre Mutter. [...] - Jetzt denken die Leute, ihr habt nichts anzuziehen. Ich hab euch doch alles auf dem Sessel hingelegt. [...] Ich hörte ihnen zu, bemüht, nicht ihre Aufmerksamkeit zu erregen, und dachte daran, wie Kinder sein können. $(\mathrm{G}, 61)$

Die Thematisierung von Kriegsidentität markiert die Heimgekehrten in allen drei Werken als durch den Krieg stark in Mitleidenschaft gezogen und dadurch auch als Opfer. Auf unterschiedlichen Ebenen wird Identitätsverlust konstatiert; dabei zeichnet sich jeweils eine Eigendynamik zwischen unterschiedlichen Stadien ab, die im Krieg beginnen und sich nach der Rückkehr fortsetzen. Extreme Angstsituationen und die Befehle, unmenschliche Handlungen auszuführen, lösen psychische Mechanismen wie Gefühls- und Bindungslosigkeit, Hypervigilanz und Schlaflosigkeit aus; durch den Konsum von Drogen und Medikamenten werden diese kurzfristig gelindert, langfristig jedoch verstärkt. Nach dem Krieg kommt noch die Schwierigkeit einer durch die Persönlichkeitsveränderung erschwerten Eingliederung in das private Umfeld und die Zivilgesellschaft hinzu.

Unterschiede zwischen den dokumentarischen, autobiografischen und fiktionalen Ansätzen von Aleksievič, Šehić und Gelasimov werden hier darin deutlich, dass die ersten beiden Autor^innen stärker auf konkrete Kriegsfolgen eingehen, während Gelasimov seine Leser`innen aus größerer Distanz auf die Kriegsvergangenheit seiner Hauptfigur blicken lässt, indem er zusätzliche Themen aus anderen Lebensbereichen in die Handlung einflicht. Dadurch erscheint es einfacher, die traumatische Vergangenheit in einem Prozess der Aufarbeitung zu verorten. Keiner der Texte zielt darauf ab, Opferdiskurse in eine Richtung zu lenken, die auf Rechtfertigung abzielt oder Anschuldigungen gegen konkrete Täter vorbringt; die Botschaft ist dagegen vielmehr jene, dass es im Krieg nur Verlierer und Opfer gibt. Im Zentrum stehen jeweils große Betroffenheit und die Intention, ein gesellschaftliches Bewusstsein für die Problematik zu schaffen, was auch der einzige Weg zu sein scheint, persönlichem und kollektivem Identitätsverlust sowie gesellschaftlichem Ausschluss entgegenzuwirken. Den Texten ist damit das Anliegen gemein, gegen soziale Ungerechtigkeit anzuschreiben, wobei eine unnötig starke Thematisierung von Opferrollen vermieden wird. 


\section{Erinnerungskultur}

Neben der persönlichen Situation ehemaliger Kriegsteilnehmer zeichnen sich bei Aleksievič, Šehić und Gelasimov im Hintergrund auch Tendenzen einer individuell geprägten Erinnerungskultur ab: das Bestreben nämlich, das Andenken an verstorbene Freunde, doch auch an flüchtige Bekannte in Ehren zu halten. Das offizielle und private historische Bewusstsein über das jeweilige Ereignis ist in den betroffenen Ländern unterschiedlich ausgeprägt. Dabei verfolgen alle drei Texte zum einen das Anliegen, staatliche Fehlinformationen zu korrigieren sowie zum anderen, die individuelle Dimension von Verlust und Trauer sichtbar zu machen. Erste Denkmäler für die gefallenen Soldaten des Afghanistankrieges wurden in der Sowjetunion erst seit Mitte der 1990er Jahre aufgestellt; nach dem Zerfall der Sowjetunion - d.h. im Entstehungskontext der Werke von Aleksievič und Gelasimov - orientierte sich unter Boris El'cin und Vladimir Putin die staatliche Gedenkkultur wieder zunehmend stärker am heroischen Gedenken an den ,Großen Vaterländischen Krieg‘ (Hausmann 2013, 430-431).

Für Aleksievičs Aufarbeitung des Afghanistan-Kriegs betrifft dies zunächst Zensur und Propaganda in sowjetischen Medienberichten über die Einsätze und die Verschleierung der ,Todesursache“ Krieg auf den Grabsteinen; beides tilgt den Anspruch der Betroffenen auf den Status eines Opfers:

\footnotetext{
Еще никто не видел цинковых гробов. Это потом мы узнали, что гробы уже в город привозили, но хоронили тайком, ночью, на могильных плитах писали „умер“, а не „погиб“. (А, 16)
}

Noch hatte keiner Zinksärge gesehen. Erst später haben wir erfahren, dass solche Särge schon in der Stadt eingetroffen waren, aber sie wurden nachts heimlich in die Erde gelassen, auf den Grabsteinen stand „gestorben“ und nicht „gefallen“. (A, 35)

Als die Politik des Verschweigens dennoch bekannt wird, kommt dazu noch eine allgegenwärtige Ungewissheit über die Schicksale Angehöriger: „Рассказывают случай: привезли матери гроб, она его похоронила. А через год сын возвращается...“ (А, 77) [„Ich habe gehört, dass einer Mutter der Sarg mit dem Sohn darin gebracht wurde, sie begrub ihn, und ein Jahr später kam er lebend wieder, er war nur verwundet gewesen“ $(\mathrm{A}, 116)]$.

Auch nachträglich kommt es noch zu Umwertungen der historischen Ereignisse:

Уже говорят, что это была политическая ошибка. Сегодня тихо говорят, завтра будут громче. А я там кровь оставил... Свою... И чужую... Нам давали ордена, которые мы не носим... Мы еще будем их возвращать... Ордена, полученные честно на нечестной войне... (А, 18) 
Heute heißt es bereits, das Ganze sei ein politischer Fehler gewesen. Ich habe dort Blut vergossen - meins und fremdes. Wir haben Orden gekriegt, die wir nicht tragen. Wir werden sie noch zurückgeben... Orden, ehrlich erworben in einem unehrenhaften Krieg... (A, 38-39)

Zwar handelt es sich hier um eine Berichtigung von zuvor bewusst falsch kommunizierten historischen Fakten, doch geschieht dies auf eine unsensible Weise, die den Identitätsverlust Betroffener durch die unklare Einordnung verstärkt. Da die politischen Entscheidungsträger im postsowjetischen Kontext weiterhin nicht zur Verantwortung gezogen werden, erfolgt die Neubewertung des Krieges auf Kosten der einfachen Soldaten und zieht Gegenreaktionen jener nach sich, die sich an den Heldenstatus ihrer Angehörigen klammern. Wie besonders in den Vorwürfen gegen Aleksievič deutlich wird, wendet man sich zu dessen Verteidigung auch gegen die Wahrheit:

Вы говорите, что я должна ненавидеть государство, партию... А я горжусь своим сыном! Он погиб, как боевой офицер. Его все товарищи любили. Я люблю то государство, в котором мы жили - СССР, потому что за него погиб мой сын. А вас ненавижу! Мне не нужна ваша страшная правда. Она нам не нужна!! Слышите?! (А, i)

Sie sagen, ich soll den Staat und die Partei hassen... Aber ich bin stolz auf meinen Sohn! Jawohl, ich bin stolz auf ihn! Er ist im Kampfeinsatz gestorben, als Offizier. Alle seine Kameraden haben ihn geliebt. Ich liebe den Staat, in dem wir lebten - die UdSSR, weil mein Sohn für ihn gestorben ist. Aber Sie hasse ich! Ich brauche Ihre schreckliche Wahrheit nicht! Wir brauchen Sie nicht!! Hören Sie?! (A, 241)

Šehić thematisiert aus seiner persönlicheren Perspektive Halbwahrheiten, welche die öffentliche Meinung im Umgang mit dem Bosnien-Krieg prägen. Trotz des Wissens um die Sinnlosigkeit der Kampfhandlungen wendet sich die Gesellschaft mit dem Vorwurf der Feigheit gegen Deserteure:

Divno je biti izbjeglica.

To znači, da si građanin petnaestog reda.

Niko te ne poznaje.

Možeš se popišati nasred ulice.

I nastaviti hodati dalje. (̌̌, 70)

[Es ist wunderbar, ein Deserteur zu sein.

Das heißt, dass du ein Bürger fünfzehnter Klasse bist.

Niemand kennt dich.

Du kannst dich auf offener Straße anpinkeln.

Und einfach weitergehen.]

Eine wichtige Gemeinsamkeit von Propaganda, Nationalismus und falscher Berichterstattung besteht sicherlich darin, dass Akteure als Vertreter einer Gruppe, 
selten jedoch als Individuen behandelt werden. Ein erster Ansatz, dem entgegenzuwirken, besteht im Hinweis darauf, dass die einzelnen Kriegsteilnehmer höchst unterschiedlich waren:

Там разные люди были. Не представляйте нас одинаковыми. А то сначала о нас молчали, потом стали воображать всех героями, теперь ниспровергают, чтобы следом забыть. Там же один мог лечь рывком на мину и спасти даже незнакомых ему ребят, другой подойти к тебе и просить: „Хотите, стирать вам буду, только не посылайте на боевые.“ (А, 82)

Es gab die unterschiedlichsten Leute dort. Denken Sie nicht, dass wir alle gleich waren. Zuerst hat man uns totgeschwiegen, dann waren wir auf einmal Helden und jetzt diffamiert man uns, um uns schließlich ganz zu vergessen. In Afghanistan kam es vor, dass sich einer auf eine Mine warf, um unbekannte Soldaten zu retten, aber es gab auch welche, die baten „Schicken Sie mich bloß nicht in Kampfhandlungen, ich wasche Ihnen auch die Sachen.“ (A, 123)

Eine ähnliche Individualisierung identitätsloser Heimkehrer nimmt Gelasimovs Hauptfigur auf aktive Weise vor, als sie ihre bereits vor dem Kriegseinsatz entwickelte Zeichenbegabung wiederaufnimmt. Die Zeichnungen von Kriegsepisoden und Menschen unterstützen zum einen die Selbstfindung dieser Figur, zum anderen werden dadurch auch die Verluste von Kameraden aufgearbeitet; in Form von Modifizierungen und Ergänzungen der Bildmotive wird unwiederbringlich Verlorenes traumatherapeutisch wirksam neu geschaffen:

- Подожди, а это чего? - Это наш лейтенант. Со своими детьми. - Так его же убили. [...] И детей у него не было. - Ну и что? - говорю я. - А здесь он с детьми. [...] Генка долго молчит, смотрит на мои рисунки. - Ты, знаешь, чего? - наконец говорит он. Дай их мне. Все. (G, 292)

- Moment mal, wer ist das denn? - Unser Leutnant. Mit seinen Kindern. - Er ist doch gefallen. [...] Und Kinder hatte er auch keine. - Na und? sage ich. - Hier hat er eben welche. [...] - Weißt du was? sagt er schließlich. - Gib sie mir. Alle. (G, 89)

Gelasimov verschiebt den Fokus so von kollektiven Zuschreibungen, die, wie im vorhergehenden Kapitel beschrieben, in seiner Novelle ebenfalls impliziert sind, auf die individuelle Selbstfindung. In Hinblick auf Opferdiskurse zeigt die literarisch reflektierte offizielle Erinnerungskultur Russlands Bestrebungen, ehemalige Kriegsteilnehmer entweder zu glorifizieren, wobei Umdeutungen der Geschichte ohne Weiteres in Kauf genommen werden, oder aber die traumatisierten Heimkehrer vollständig aus dem öffentlichen Raum auszuschließen, was ein Verschweigen der historischen Ereignisse impliziert. Beide Strategien dienen zur Vermeidung sowohl von Opfern mit dem Anspruch auf Entschädigung als auch von Tätern als Produkt einer politischen Entscheidung. Alle drei Autor^innen 
positionieren sich kritisch gegen diese Verfälschungspraktiken und entgegnen ihnen durch den Versuch, die tatsächlichen Umstände der entsprechenden Kriege zugänglich zu machen. Dennoch werden zugleich Versuche erkennbar, die Soldaten von ihrer Last zu befreien und sie beim Wiederfinden ihrer Identität zu unterstützen. Aleksievič leistet ihren diesbezüglichen Beitrag hauptsächlich durch das Anhören und Ordnen fremder Geschichten, Šehić befreit sich durch unzensiertes Erzählen von seiner eigenen Last und Gelasimov erfindet einen feinfühligen Kriegsheimkehrer, der das individuelle und kollektive Trauma durch sein Zeichnen auf künstlerisch-therapeutische Weise verarbeitet.

\section{Gedenken, Trauer und Wiederfinden der Identität fernab von Opfer- und Täterdiskursen}

Neben Thematisierungen der öffentlichen Meinung und offizieller Gedenkveranstaltungen sind alle drei Texte auch per se als Medien des Gedenkens zu verstehen. So integriert Aleksievič etwa persönliche Grabesinschriften in ihren Roman der Stimmen. Diese stammen von den Eltern und zeigen, wie unterschiedlich, wenngleich stets liebevoll, die Tode dieser jungen Männer von ihren engsten Angehörigen verarbeitet werden. Dabei wird der Kriegseinsatz meist als Erfüllung einer ,internationalistischen Pflicht` deklariert. Neben dem intim-familiären steht daher auch der heroische sowjetische Diskurs; durch die Thematisierung von Schutzlosigkeit und Unerfahrenheit der jung Verstorbenen erscheint Letzterer jedoch deutlich abgeschwächt. Das intim-familiäre Gedenken und die damit verbundene Integration persönlicher Gefühle wie Trauer, Erschütterung und Liebe eröffnen jeweils einen Blickwinkel, der sowohl Opfer- als auch Täterdiskurse in den Hintergrund rückt, weil hier der Wert des Individuums unabhängig von seiner Funktion innerhalb staatlicher Kollektive reflektiert wird.

ЛАДУТЬКО

АЛЕКСАНДР ВИКТОРОВИЧ

(1964-1984)

Погиб при исполнении

интернационального долга.

Ты честно выполнил свой воинский

долг. Себя уберечь, мой сыночек,

не смог. На афганской земле ты погиб,

как герой, чтоб мирное небо было

над страной.

Дорогому сыночку от мамы. (A, i) 


\author{
LADUTKO \\ ALEXANDER VIKTOROWITSCH \\ (1964-1984) \\ Gefallen in Erfüllung \\ seiner internationalistischen Pflicht. \\ Du hast ehrlich deine soldatische \\ Pflicht erfüllt. Dich zu schützen \\ hast du nicht vermocht, mein lieber Sohn. \\ Auf afghanischem Boden bist du gefallen \\ als Held, für einen friedlichen Himmel \\ über dem Land. \\ Meinem lieben Sohn von seiner Mama. (A, 230)
}

ТАТАРЧЕНКО

ИГОРЬ ЛЕОНИДОВИЧ

(1961-1981)

Выполняя боевое задание, верный

воинской присяге, проявив стойкость

и мужество, погиб в Афганистане.

Любимый Игорек,

ты ушел из жизни, не познав ее.

Мама, папа. (A, i)

TATARTSCHENKO

IGOR LEONIDOWITSCH

(1961-1981)

Bei Erfüllung eines Kampfauftrages seinem

Soldateneid treu, mutig und standhaft, gefallen in Afghanistan.

Geliebter Igorjok,

$\mathrm{du}$ bist aus dem Leben gegangen,

ohne es kennengelernt $\mathrm{zu}$ haben.

Mama, Papa. (A, 230)

Bereits in der ersten Auflage von Cinkovye mal'čiki stellt Svetlana Aleksievič den Erinnerungstexten die Tagebuchaufzeichnungen von ihrer journalistischen Reise nach Afghanistan voran. Diese enthalten zur Erinnerung an ihre im Haupttext anonymisierten Gesprächspartner`innen eine Art Gedenktafel:

Не называю в книге подлинных имен. [...] А в дневнике я сохранила фамилии. Может, когда-нибудь мои герои захотят, чтобы их узнали: Сергей Амирханян, капитан; Владимир Агапов, старший лейтенант, начальник расчета; Татьяна Белозерских, служащая; Виктория Владимировна Барташевич, мать погибшего рядового [...]. (А, 11) 
Ich nenne im Buch nicht die wahren Namen. [...] Aber im Tagebuch habe ich ihre Namen festgehalten. Vielleicht wollen meine Helden einst, dass man sie erfährt: Sergej Amirchanjan, Hauptmann; Wladimir Agapow, Oberleutnant, Leiter einer Gefechtsbesatzung; Tatjana Beloserskich, Zivilbeschäftigte; Viktoria Wladimirowna Bartaschewitsch, Mutter eines gefallenen Soldaten [...]. (A, 29)

Die Texte von Gelasimov und Šehić enthalten ähnliche Momente des Gedenkens. In $\check{a} a \check{d} d a$ wird eine solche Intention anhand der Zeichnungen der Hauptfigur erkennbar, die sowohl flüchtige als auch längerfristige Bekannte aus dem Krieg vor dem Vergessen bewahren. Pod pritiskom enthält einen längeren Abschnitt, in dem reale Menschen und Ereignisse aufgezählt werden. Außerdem hält die Überschrift fest, dass diese Geschichte existiert, d.h. dass alles Aufgelistete tatsächlich passiert ist und erlebt wurde:

postoji ova priča

[...]

Postoji mrtav neprijateljski vojnik pokraj školske zgrade: ko prođe pored njega obavezno mu sruči rafal u glavu. Postoje puške i bombe i meci u crnim okvirima.

Postojidrvećekojeložimoulimenimpećicama,ionotakodirektnoodlaziurajzadrveće,prolazeći kroz oblake lišene bilo kakve funkcije sem da plutaju neumoljivo kao ravna linija EKG-a.

Postojao je neko vrijeme patriotizam u meni, a onda je sve ošlo u kurac. [...]

Postoje grbovi, zastave, činovi, novčane nagrade, vojne formacije, ratni zanos, patriotske pjesme, znoj ispod pazuha [...]. (̌̌, 138)

[Es gibt diese Geschichte

[...]

Es gibt einen toten feindlichen Soldaten neben dem Schulgebäude: wer an ihm vorbeigeht, schießt ihm eine Gewehrsalve in den Kopf. Es gibt Kanonen und Bomben und Granaten in schwarzen Hülsen.

Es gibt Brennholz, das wir in die Blechöfen legen, sodass es direkt in den Brennholzhimmel auffährt, durch die Wolken, jeder Funktion entledigt, außer unerbittlich zu treiben wie die gerade Linie eines EKG.

Irgendwann gab es in mir Patriotismus, dann ist er zum Teufel gegangen. [...]

Es gibt Wappen, Flaggen, Dienstgrade, monetäre Belohnungen, Kampfformationen, Kriegsbegeisterung, patriotische Lieder, Achselschweiß [...].]

Ein weiteres Fragment in Šehićs Text trägt den Titel kaleidoskop sjećanja [Kaleidoskop der Erinnerungen]. Es handelt sich um eine autobiografische Skizze, die bei der Kindheit beginnt und damit einen ersten Schritt setzt, die durch den Krieg unterbrochene persönliche Lebensgeschichte wieder als Kontinuum zu betrachten:

U momentu rođenja (14.04.1970) težak sam 3.800 grama. Dugačak $42 \mathrm{~cm}$. Ja sam dijete aprila. Kao što svi znamo, travanj je mjesec mrtvih. [...] Vrijeme je da zaronim u djetinjstvo kao u osvježavajuće hladan zelenac Une. (ك̌, 129) 
[Als ich geboren wurde (14.04.1970), wog ich $3.800 \mathrm{Gramm}$ und war $42 \mathrm{~cm}$ groß. Ich bin ein April-Kind. Wie wir alle wissen, ist April der Monat der Toten. [...] Es wird Zeit, dass ich in die Kindheit eintauche wie in das erfrischend kalte Grün der Una.]

Das Eintauchen in Erinnerungen an die Kindheit, die Šehić mit dem Wasser des Flusses Una vergleicht, stellt ein belebendes Element inmitten der Lethargie dar. Zugleich hält der Autor fest, er habe kein Interesse an seiner Kindheit, denn diese gleiche verbrannten Fotografien, an die er sich ausschließlich in Form von Flashbacks erinnere (̌́, 130). Diese Abwehrhaltung hat wohl mit dem Entstehungskontext von Pod pritiskom zu tun, das zu einer Zeit verfasst wurde, als die traumatisierende Kriegserfahrung noch alles überschattete. Gerade die Kindheit am Fluss Una wird in späteren Texten sehr präsent und erweist sich als emotionaler Ruhepol mit therapeutischer Wirksamkeit. Sowohl in Gedichtbänden wie Moje rijeke (2014) als auch in dem 2015 erschienenen Prosaband Knjiga o Uni wird dies deutlich. Auch in einem Interview bestätigt Šehić die Bedeutung der Una für ihn und andere:

Rijeka Una je prirodna pojava tvrđa od granita, jer je ništa ne može uništiti. U ratu smo je još više cijenili i voljeli, jer joj rat nije mogao ništa. Dolazili smo na kupanje u skrivene rukavce [...]. Una je kult i magija. Ona, takva neranjiva, predstavlja metafizički dom. Njena boja i njen tok nisu bili ništa manje lijepi tokom rata. Ljudi su rizikovali život da bi išli na kupanje pod granatama i snajperima. (Raljević et al. 2017, 5)

[Der Fluss Una ist eine Naturerscheinung härter als Granit, nichts kann ihn zerstören. Im Krieg haben wir ihn noch mehr geschätzt und geliebt, denn der Krieg konnte ihm nichts anhaben. Wir badeten in den versteckten Flussarmen [...]. Die Una ist Kult und Magie. Aufgrund ihrer Unverwundbarkeit ist sie wie ein metaphysisches Haus. Ihre Farbe und ihr Lauf waren auch im Krieg um nichts weniger schön. Menschen riskierten ihr Leben, um unter Granaten und Heckenschützen schwimmen zu gehen.]

Valentina Rossi geht ausführlich auf die starke Präsenz von Kindheit und Kindern in Žažda ein, während der Krieg unsichtbar bleibe (2012). Der Wiederaufbau von Identität wird in diesem Text ebenfalls über die Rekonstruktion einer Verbindung zur Kindheit ermöglicht. Die Kontinuität zwischen der Gegenwart und der Zeit vor dem Trauma wird über das Zeichnen hergestellt, das zum einen bereits damals identitätsstiftend war und bei der Bewältigung pubertärer Verunsicherung half und zum anderen auch die Beziehung zu dem unkonventionellen Schuldirektor als einer wichtigen Vertrauensperson markiert. An diese Beziehung ist zudem auch eine philosophische Sicht auf die Welt gekoppelt, die darauf beruht, genau auf Details zu achten und zugleich von Einzelheiten zu abstrahieren, um den Sinn des Lebens zu erkennen: 
Ты когда-нибудь видел, как падает луч света в темную комнату из приоткрытой двери? В самом начале он узкий, а потом расширяется. Точно так же и человек. Сначала один, потом двое детей, потом четверо внуков. Понимаешь? Человек расширяется, как луч света. До бесконечности. Ты понимаешь? (G, 237)

Hast du mal gesehen, wie ein Lichtstrahl durch eine angelehnte Tür in ein dunkles Zimmer fällt? Zuerst ist er schmal, dann wird er immer breiter. Genauso ist der Mensch. Zuerst ist er allein, dann hat er zwei Kinder, dann vier Enkel. Verstehst du? der Mensch wird immer breiter, wie ein Lichtstrahl. Bis zur Unendlichkeit. Verstehst du? (G, 28)

Alle drei Autor^innen lenken den Interessensfokus weg von Opfer-Täter-Zuschreibungen und versuchen, die Ereignisse als abstrakte Ganzheit ins Blickfeld zu rücken sowie zugleich auch deren individuelle Besonderheiten zu beleuchten. Dies bildet auch einen Ausgangspunkt für die Gefühlsarbeit, die bei Gelasimov über das Zeichnen, bei Šehić über das Erinnern an die Kindheit am Fluss Una und bei Aleksievič über das dialogische Zuhören eine Metaebene zur Handlungsebene der Texte bilden. Alle drei Perspektiven fassen die Ereignisse in den Blick, stellen jedoch das persönliche Erleben der Akteure über die Umstände selbst und widmen sich anhand dieses Prismas deren verletzlicher und verletzter Identität:

А я слежу за чувством, а не за событием. Как развивались наши чувства, а не события. Может быть, то что я делаю, похоже на работу историка, но я историк бесследного. Что происходит с большими событиями? Они перекочевывают в историю, а вот маленькие, но главные для маленького человека, исчезают бесследно. (А, i)

Ich beobachte das Gefühl, nicht das Ereignis. Wie sich unsere Gefühle entwickeln, nicht die Ereignisse. Vielleicht ähnelt das, was ich tue, der Arbeit eines Historikers, aber ich bin eine Historikerin des Spurlosen. Was geschieht mit großen Ereignissen? Sie gehen in die Geschichte ein, die kleinen aber, die jedoch für den kleinen Menschen die wichtigsten sind, verschwinden spurlos. (A, 26-27)

Diese Ebene der Gefühle ist es auch, wo Menschen am verletzlichsten sind. Dies erkennt Aleksievič in jenem Moment, als sie im Oktober 1993 den Prozess um Cinkovye mal'čiki verliert; beim Verlassen des Gerichtssaals findet sie dafür folgende Worte:

- Как человек... Я попросила прощения за то, что причинила боль, за этот несовершенный мир, в котором часто невозможно даже пройти по улице, чтобы не задеть другого человека... Но, как писатель... Я не могу, не имею права просить прощения за свою книгу. За правду! (А, i)

„Als Mensch... Als Mensch habe ich um Verzeihung gebeten dafür, dass ich Schmerz bereitet habe, für diese unvollkommene Welt, in der man oft nicht einmal die Straße entlanggehen kann, ohne einem anderen zu nahe zu kommen... Aber als Schriftstellerin kann ich nicht, habe ich nicht das Recht, für mein Buch um Verzeihung zu bitten. Für die Wahrheit!“ (A, 297) 
Der Prozess gegen Svetlana Aleksievič zeigt auf eindrückliche Weise, dass die Wahrheit des persönlichen Empfindens und jene der kollektiven Selbstverortung in der Gesellschaft nicht immer miteinander in Einklang zu bringen sind. Dies setzt sowohl der Aufarbeitung von Traumatisierungen als auch der historischen Aufarbeitung Grenzen, die nur in kleinen Schritten überwunden werden können.

\section{Opferdiskurse zwischen Zuhören, Narration und Geschichte}

Alle genannten Formen des Gedenkens enthalten konfliktbehaftete Widersprüche, da die Situation von Kriegsheimkehrern eine zwischen Opfer und Täter, Held und gesellschaftlichem Außenseiter ist. Narration, Zuhören und Geschichte bilden dabei drei Perspektiven mit unterschiedlichem Potenzial, sich diesen Widersprüchen zu nähern. Die Verletzlichsten sind jeweils die Heimgekehrten, die mit Traumatisierung und Identitätsverlust kämpfen und sich zugleich als Objekte der jeweiligen Erinnerungskultur wiederfinden.

Gelasimovs fiktionaler Text hat hier gewissermaßen den Vorteil, dass keine konkreten Akteure mit diesen Verortungen und Zuschreibungen von außen assoziiert sind. Demgegenüber bieten sowohl Šehićs autobiografisches als auch Aleksievičs dokumentarisches Schreiben den Erzählenden die Möglichkeit, ihre Traumatisierungen öffentlich zu reflektieren und sich dabei - möglicherweise in kleinen Schritten deren Überwindung anzunähern. In allen drei Fällen sind eine empathische Zuhörerhaltung und ein an Wahrheit interessiertes Erzählen notwendig, die trotz der unterschiedlichen Genres auch jeweils erreicht werden, was jedoch nur dadurch möglich ist, dass die Geschichte in den Hintergrund tritt, um die beschriebenen Menschen als emotional fühlendes Zentrum sichtbar zu machen.

Zwischen Schreiben und Erzählen findet so jeweils ein wichtiges Stück Gefühlsarbeit statt, das zu einer anderen Form von Wahrheit führt, als durch Kriegsakten und mediale Diskurse zugänglich ist. Werturteile für oder gegen Menschen weichen dem Blick auf Dynamiken politischer Entscheidungen und menschlichen Handelns sowie auf die Verletzlichkeit aller Beteiligten. Durch den individuellen Zugang und die Auflösung der Kategorien von Opfer und Täter, Held und Außenseiter wird daher, wie die ähnlichen Erfahrungen zahlreicher unterschiedlicher Zeugen nahelegen, die Geschichte nicht verfälscht, sondern auf neue Weise zugänglich. 


\section{Literaturverzeichnis}

Aleksievič, Svetlana. Cinkovye mal'čiki. Moskva: Molodaja gvardija, 1991.

Aleksievič, Svetlana. Cinkovye mal'čiki. Ispravlennaja avtorskaja redakcija. 2006, http://www. lib.ru/NEWPROZA/ALEKSIEWICH/aleksiewich.txt (31. Oktober 2018).

Aleksijewitsch, Swetlana. Zinkjungen. Afghanistan und die Folgen. Übers. von Ingeborg Kolinko und Ganna-Maria Braungardt. Berlin: Suhrkamp, 2016.

Assmann, Aleida. Geschichte im Gedächtnis: Von der individuellen Erfahrung zur öffentlichen Inszenierung. München: C. H. Beck, 2014.

Bahro, Steffi. „,Du kannst heim gehen': Perspektiven frühneuzeitlicher Kriegsheimkehr im Märchen“. Figurationen der Heimkehr: Die Passage vom Fremden zum Eigenen in Geschichte und Literatur der Neuzeit. Hg. Sünne Juterczenka und Kai Marcel Sicks. Göttingen: Wallstein, 2011. 111-127.

Frenzel, Elisabeth. „Heimkehrer“. Motive der Weltliteratur: Ein Lexikon dichtungsgeschichtlicher Längsschnitte. 5., überarbeitete und ergänzte Auflage. Stuttgart: Kröner, 1999. 328-340.

Gelasimov, Andrej. „Žažda“. Žažda. Avtorskij zbornik. Hg. Andrej Gelasimov. Moskva: Ėksmo, 2011 [2002]. 219-313.

Gelassimow, Andrej. Durst. Übers. von Dorothea Trottenberg. Berlin: Suhrkamp, 2011.

Goltermann, Svenja. „Zwischen den Zeiten: Deutsche Soldaten und ihre Heimkehr aus dem Zweiten Weltkrieg“. Figurationen der Heimkehr: Die Passage vom Fremden zum Eigenen in Geschichte und Literatur der Neuzeit. Hg. Sünne Juterczenka und Kai Marcel Sicks. Göttingen: Wallstein, 2011. 145-161.

Hausmann, Guido. „Sowjetunion/Russland: Die unfriedliche Zeit: Politischer Totenkult im 20. Jahrhundert“. Gefallenengedenken im politischen Vergleich: Nationale Tradition, politische Legitimation und Individualisierung der Erinnerung. Hg. Manfred Hettling und Jörg Echternkamp. München: Oldenbourg, 2013. 423-440.

Homer. Odyssee. Übersetzung, Nachwort und Register von Roland Hampe. Stuttgart: Reclam, 2004.

Levine, Peter. Trauma und Gedächtnis: Die Spuren unserer Erinnerung in Körper und Gehirn. Wie wir traumatische Erfahrungen verstehen und verarbeiten. München: Kösel, 2015.

Raljević, Selma, Džemal Bijedić und Faruk Šehić. „Sci-Fi je proročanska vrsta književnosti: Intervju s Farukom Šehićem “. [sic] - a journal of literature, culture and literary translation 1.8 (2017): 1-19.

Rossi, Valentina. „La storia di quattro reduci: Žažda (Sete) di Andrej Gelasimov“. Lingue e letterature d'Oriente e d'Occidente 1.1 (2012): 303-328.

Šehić, Faruk. „Pod pritiskom“. Hit depo. Pod pritiskom. Transsarajevo. Apokalipsa iz Recycle bina. Hg. Faruk Šehić. Sarajevo: Buybook, 2008. 63-193.

Šehić, Faruk. Moje rijeke. Sarajevo: Buybook, 2014.

Šehić, Faruk. Knjiga o Uni. Četvrto dopunjeno izdanje. Sarajevo: Buybook, 2015.

Sicks, Kai Marcel, und Sünne Juterczenka. „Die Schwelle der Heimkehr: Einleitung“. Figurationen der Heimkehr: Die Passage vom Fremden zum Eigenen in Geschichte und Literatur der Neuzeit. Hg. Sünne Juterczenka und Kai Marcel Sicks. Göttingen: Wallstein, 2011. 9-29.

Sivuda, Olena. „,Vozvraščenie“ von Andrej Platonov und ,Sud'ba čeloveka‘ von Michail Šolochov im Kontext der sowjetischen Heimkehrerliteratur“. Slavische Identitäten: Paradigmen, Poetiken, Perspektiven. Hg. Gernot Howanitz, Christian Kampkötter und Heinrich Kirschbaum. München u.a.: Sagner, 2014. 127-137. 
Welch, David. „Gray Propaganda“. Propaganda and Mass Persuasion: A Historical

Encyclopedia, 1500 to the Present. Hg. Nicolas Cull, David Culbert und David Welch. Santa Barbara u.a.: ABC Clio, 2003. 151-153.

Weltgesundheitsorganisation (WHO). ICD-10: Internationale Klassifikation psychischer Störungen. 10. Auflage. Übers. und hg. von H. Dilling, W. Mombour und M. H. Schmid. Bern: Hogrefe, 2015. 
